\title{
A new function for the fragile $X$ mental retardation protein in regulation of $P S D-95$ mRNA stability
}

\author{
Francesca Zalfa ${ }^{1,2,6}$, Boris Eleuteri ${ }^{1,2,6}$, Kirsten S Dickson ${ }^{3,6}$, Valentina Mercaldo ${ }^{1,2}$, Silvia De Rubeis ${ }^{1,2}$, \\ Alessandra di Penta ${ }^{2}$, Elisabetta Tabolacci ${ }^{4}$, Pietro Chiurazzi ${ }^{4}$, Giovanni Neri ${ }^{4}$, Seth G N Grant ${ }^{3,5}$ \& \\ Claudia Bagni ${ }^{1,2}$
}

Fragile $X$ syndrome (FXS) results from the loss of the fragile $X$ mental retardation protein (FMRP), an RNA-binding protein that regulates a variety of cytoplasmic mRNAs. FMRP regulates $m R N A$ translation and may be important in mRNA localization to dendrites. We report a third cytoplasmic regulatory function for FMRP: control of mRNA stability. In mice, we found that FMRP binds, in vivo, the mRNA encoding PSD-95, a key molecule that regulates neuronal synaptic signaling and learning. This interaction occurs through the $3^{\prime}$ untranslated region of the PSD-95 (also known as Dlg4) mRNA, increasing message stability. Moreover, stabilization is further increased by mGluR activation. Although we also found that the PSD-95 mRNA is synaptically localized in vivo, localization occurs independently of FMRP. Through our functional analysis of this FMRP target we provide evidence that dysregulation of mRNA stability may contribute to the cognitive impairments in individuals with FXS.

FXS is caused by a trinucleotide expansion in the X-linked fragile $\mathrm{X}$ mental retardation gene (FMR1) that leads to the subsequent loss of FMRP, and it is the most common cause of X-linked mental retardation. FMRP has multiple RNA-binding motifs and is thought to be involved in mRNA localization and translational regulation in neurons, two processes required for synaptic plasticity (reviewed in ref. 1). Because the only obvious abnormality in the brains of individuals with FXS is the presence of longer, immature-appearing spines ${ }^{1}$, current models have focused on the possible dysregulation of synaptic mRNAs as an underlying cause of FXS mental deficits.

A wide variety of mRNAs have been identified as potential targets of mammalian FMRP, both in vitro and in vivo ${ }^{2,3}$. FMRP binds various mRNA elements ${ }^{1}$, including a G-rich RNA structure (G-quartet) ${ }^{4-6}$ and U-rich stretches ${ }^{7}$. FMRP is also indirectly recruited to some target mRNAs via binding to the noncoding RNAs BC1 and $B C 200$ (refs. 8-11). Finally, both mammalian and Drosophila FMRP are present in microRNA (miRNA) complexes ${ }^{12}$ and may be recruited to mRNAs that are bound to miRNAs.

In the FMRP protein, the RGG box recognizes G-quartet sequences present in some FMRP targets ${ }^{4}$, whereas the N-terminus recognizes a bulge in $B C$ RNAs $^{10}$. Notably, although FMRP contains two KH domains, a known RNA-binding motif, no endogenous neuronal targets that are recognized by this domain have been identified ${ }^{13}$. Functionally, FMRP acts as a translational repressor of a subset of neuronal mRNAs ${ }^{3}$, and it may be involved in synaptic mRNA localization, as FMRP is present in mRNP localization complexes ${ }^{14}$.
A limited number of studies also suggest that FMRP may regulate transcription ${ }^{15-17}$.

Despite much research, it remains unclear precisely how the loss of FMRP leads to alterations in the neuronal mechanisms responsible for cognition. One proposal suggests that alterations in metabotropic glutamate receptor (mGluR)-mediated signaling might underlie a number of the cognitive deficits associated with $\mathrm{FXS}^{18}$. Disruption of NMDA receptors ${ }^{19}$ or associated signaling components ${ }^{20-22}$ can also lead to impairments in synaptic plasticity. Notably, mGluRs and NMDA receptors coexist in a large-scale signaling complex ${ }^{23}$. PSD-95 (DLG4), a component of the MAGUK family of adaptor proteins that includes SAP102 (DLG3) and PSD-93, binds directly to the NMDA receptor and links other adaptors to $\mathrm{mGluRs}^{24}$. Mice lacking PSD-95 have impairments in learning ${ }^{20}$ and cortical plasticity ${ }^{21}$. Similarly, SAP102 mutant mice show learning impairments ${ }^{25}$, and mutations in human SAP102 are implicated in mental retardation ${ }^{26}$. Notably, PSD-95 mutant mice also show dendritic spine abnormalities in the striatum and hippocampus ${ }^{27}$, one of the key alterations seen in humans with FXS and in FMRP mutant mice ${ }^{1}$. A quantitative neuroimaging study also found larger right and left hippocampal volumes in individuals with FXS compared with controls, suggesting that this region may be involved in the behavioral and cognitive abnormalities associated with $\mathrm{FXS}^{28}$.

One report has indicated that FMRP regulates PSD-95 protein levels in response to mGluR signaling ${ }^{29}$. However, putative FMRP-binding sites were identified by sequence analysis, and direct interactions

\footnotetext{
${ }^{1}$ Dipartimento di Biologia, Università “Tor Vergata”, Via della Ricerca Scientifica 1, 00133 Rome, Italy. ${ }^{2}$ Istituto di Neuroscienze Sperimentali, Fondazione Santa Lucia, Via del Fosso di Fiorano 63, 00143 Rome, Italy. ${ }^{3}$ Division of Neuroscience, University of Edinburgh, George Sq., Edinburgh EH8 9JZ, UK. ${ }^{4}$ Istituto di Genetica Medica, Università Cattolica, Largo F. Vito 1, 00168 Rome, Italy. ${ }^{5}$ Wellcome Trust Sanger Institute, Hinxton, Cambridgeshire CB10 1 SA, UK. ${ }^{6}$ These authors contributed equally to this work. Correspondence should be addressed to C.B. (claudia.bagni@uniroma2.it) or K.S.D. (dickson.kris@gmail.com).
}

Received 11 December 2006; accepted 14 March 2007; published online 8 April 2007; doi:10.1038/nn1893 
a

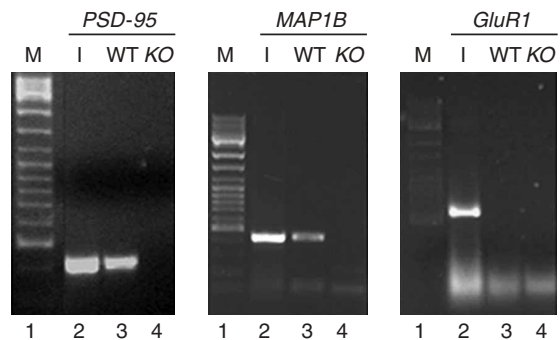

C

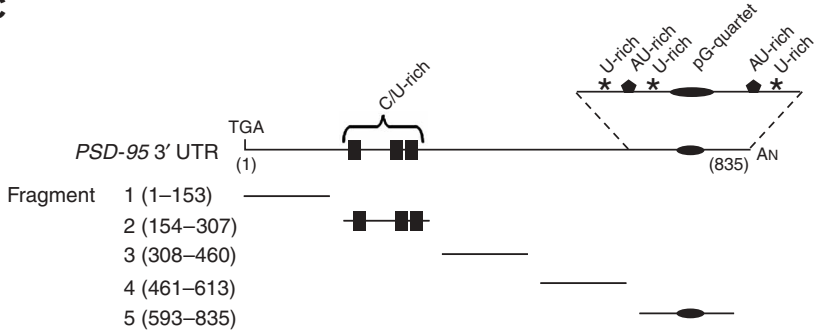

b

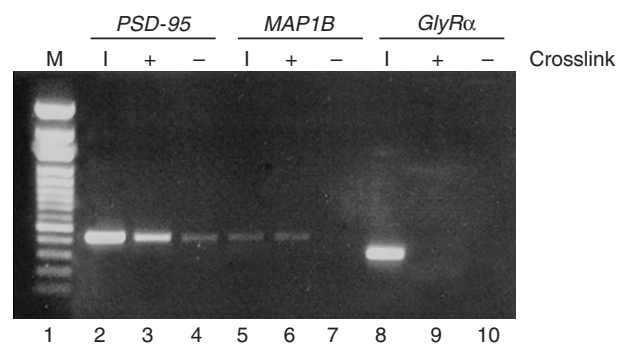

d

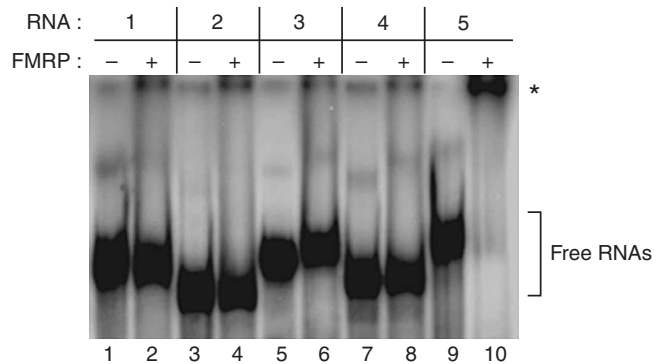

Figure 1 FMRP interacts directly with the 3' UTR of PSD-95 mRNA. (a) Brain lysates from wild-type (WT) and FMR1 knockout mice (KO) were immunoprecipitated with FMRP antibodies. RT-PCR was performed using oligonucleotides specific for the PSD-95, MAP1B and G/uR1 mRNAs. Input (1/5) is reported in lane 2. Lanes that were not relevant to this experiment were removed between the marker and lanes 1 and 2. (b) CLIP assay. Hippocampal cell extracts were immunoprecipitated with FMRP antibodies. RT-PCR was performed using oligonucleotides for the PSD-95, MAP1B and GlyR $\alpha$ mRNAs. Input (1/5) is reported in lanes 2, 5 and 8. (c) PSD-95 3' UTR fragments used in EMSA experiments. Potential functional motifs are indicated. (d) ${ }^{32} \mathrm{P}-$ radiolabeled fragments (1-5) of the PSD-95 3' UTR were incubated in the presence of FMRP (+, lanes 2, 4, 6, 8 and 10). Control reactions were performed in buffer alone (-, lanes 1, 3, 5, 7 and 9). RNA-protein complexes were resolved on native polyacrylamide gel. Unbound RNA fragments (]) and RNA-protein complexes ( $\left.{ }^{*}\right)$ are indicated.

between the PSD-95 mRNA and FMRP were not tested. Although the authors concluded that these effects were due to translational regulation of PSD-95 mRNA, the above mentioned results could not formally distinguish between effects on mRNA export, stability or translation.

In this study we provide a detailed assessment of the role that FMRP has in controlling PSD-95 expression. We have found that FMRP interacts directly with the $3^{\prime}$ UTR of the PSD-95 mRNA, providing evidence that FMRP is important in increasing the stability of the PSD-95 message. This stabilization is further increased by mGluR activation. These findings suggest that, in addition to dysregulation of translation targets, some of the FXS impairments may arise as a result of alterations in the stability of FMRP target mRNAs.

\section{RESULTS}

\section{PSD-95 mRNA interacts directly with FMRP}

To address whether FMRP directly regulates PSD-95 mRNA, we examined whether PSD-95 mRNA was present in the FMRP complex in mice. We found PSD-95 mRNA in FMRP immunoprecipitates from wild-type mice but not from FMR1 knockout mice (Fig. 1a). A known FMRP-interacting mRNA, MAP1B (refs. 8,30,31), was also coprecipitated (Fig. 1a), whereas a negative control mRNA (GluR1, also known as Gria1) was not (Fig. 1a). Using reversible cross-linking-immunoprecipitation (CLIP) ${ }^{32}$ from primary hippocampal neurons (Fig. 1b), we showed that FMRP bound directly to the PSD-95 mRNA, as crosslinking occurred only if FMRP and PSD-95 were in close proximity in vivo. MAP1B mRNA, but not GlyR $\alpha$ (also called Glra1) mRNA, was also cross-linked to FMRP (Fig. 1b).These data indicate that PSD-95 mRNA is part of the FMRP mRNP complex in vivo.

To map the FMRP-PSD-95 mRNA interaction, we carried out direct protein-RNA binding assays. We focused on the $3^{\prime}$ untranslated region (UTR) of PSD-95 mRNA because in silico analysis of this region had shown the presence of a putative G-quartet ${ }^{29}$ and three U-rich stretches $^{33}$ (Fig. 1c and Supplementary Fig. 1 online), sequence elements previously shown to recruit FMRP to RNAs ${ }^{4,7}$. Of the five short RNAs that spanned the entire $3^{\prime}$ UTR of the mouse PSD-95 mRNA (Fig. 1c), only fragment 5 had FMRP-binding ability in electrophoretic mobility shift assays (EMSAs) with purified baculovirus-expressed human FMRP protein (Fig. 1d). This RNA fragment was also bound by mouse brain extracts (data not shown). The lack of FMRP binding to fragments 1-4 (Fig. 1d) and the antisense strand (data not shown), and the ability of excess unlabeled fragment 5 RNA to compete, indicated that the FMRP-RNA interaction was specific and did not simply reflect general RNA affinity. The protein-binding ability of fragment 5 RNA was also specific, as it did not bind other RNA binding proteins (the microbial transcription and translation modulator NusG or the spliceosomal $15.5-\mathrm{kDa}$ (hSnu13p) protein; data not shown).

We also investigated which protein domain of FMRP (N-terminus, $\mathrm{KH} 1, \mathrm{KH} 2$ or C-terminus $)^{34}$ was involved in binding to the PSD-95 mRNA (Fig. 2a). We found that only the C-terminus contained PSD-95 mRNA-binding ability (Fig. 2b). This domain bound with high affinity, as binding remained present under high-stringency conditions (50 mM LiCl) (Fig. 2c). The binding was specific, as the C-terminus did not interact with fragment 1 , and binding to fragment 5 was competed with by excess unlabeled fragment 5 , but not fragment 1 (Fig. 2c).

We further mapped the mRNA region in fragment 5 that was responsible for FMRP binding by scrambling the G-rich region to eliminate all similarity to the G-quartet consensus and converting the U-rich regions into mixed sequences (Fig. 3a). High lithium $(50 \mathrm{mM})$, a condition that destabilizes G-quartet structures ${ }^{4,35}$, did not interfere with FMRP binding to either the wild-type (Fig. 3b) or the mutagenized fragment 5 (Fig. 3b). Notably, mutagenesis of all three U-rich regions did not prevent FMRP binding (Fig. 3b). 
a

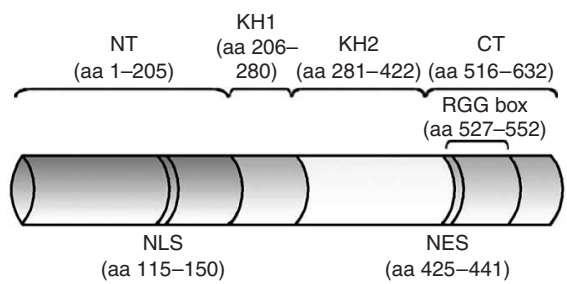

b

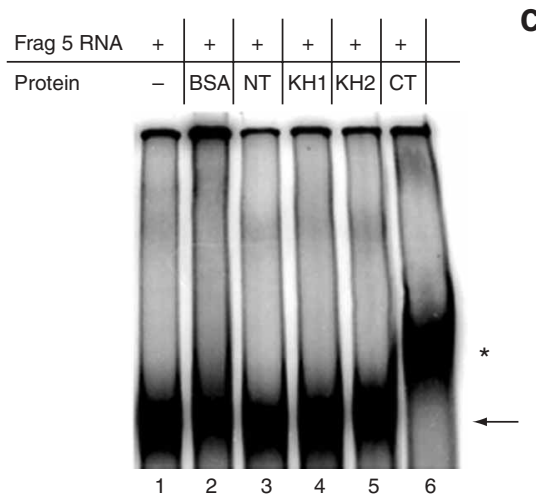

C

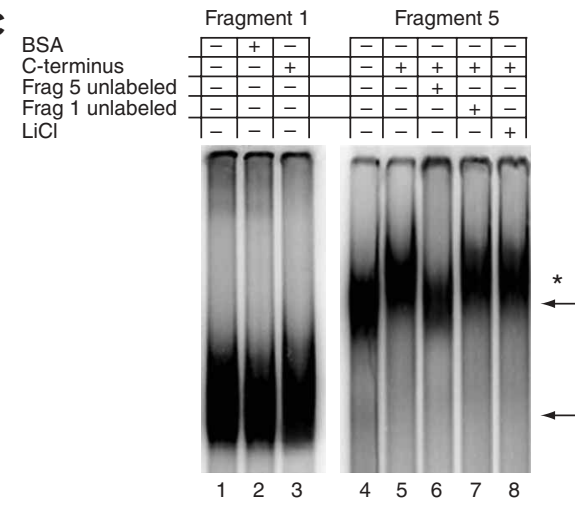

Figure 2 The $\mathrm{C}$-terminal domain of FMRP is able to specifically interact with the PSD-95 mRNA 3 UTR. (a) Schematic representation of FMRP and its principal domains: the $\mathrm{N}$ terminus (NT), $\mathrm{KH} 1$, $\mathrm{KH} 2$ and the $\mathrm{C}$ terminus (CT) containing the RGG box. The nuclear localization sequence (NLS) and the nuclear export sequence (NES) are also indicated. (b) ${ }^{32} \mathrm{P}$-radiolabeled fragment 5 of the PSD-95 3' UTR was incubated alone (lane 1), in the presence of BSA (lane 2) or in the presence of FMRP domains: $\mathrm{N}$ terminus (lane 3 ), $\mathrm{KH} 1$ (lane 4), KH2 (lane 5) and C terminus (lane 6). (c) ${ }^{32}$-radiolabeled fragments 1 and 5 of the PSD-95 3' UTR were incubated alone (lane 1 and 4 ) or in the presence of FMRP C terminus (lane 3 and 5). Fragment 1 was also incubated in the presence of BSA (lane 2). To assess the specificity of interaction between the fragment 5 and the C-terminus, we carried out the RNA binding assay in the presence of competitor RNAs (unlabeled fragment 5, lane 6; fragment 1 , lane 7 ) or in the presence of the chaotropic salt $\mathrm{LiCl}$ (lane 8). RNA-protein complexes were resolved on a native polyacrylamide gel. Unbound RNA fragments $(\leftarrow)$ and RNA-protein complexes $\left({ }^{*}\right)$ are indicated.
Because previous studies suggested that FMRP has a high affinity for poly $(\mathrm{rG})$ in vitro ${ }^{34}$, we further examined the G-rich region. Although the entire G-rich region showed binding to FMRP (Figs. 3c,d; I + II G-rich), even in the presence of high lithium salt (Fig. 3d), no binding was detected when we used two short RNA fragments (Figs. 3c,d) of that region (Fig. 3c). Our findings argue that FMRP recognizes a structured G-rich sequence in the $3^{\prime}$ UTR of the $P S D$-95 mRNA or a region spanning the two fragments, and that this structure does not form a G-quartet.

\section{Similar PSD-95 polysomal profile in wild type and knockout}

FMRP can act as a translational repressor ${ }^{3,31}$ and local translation of synaptic mRNAs has been increasingly implicated in neuronal plasticity, learning and memory formation (reviewed in ref. 36). Notably, a number of localized mRNAs encode synaptic proteins (for example, Arc, MAP1B, $\alpha$ CaMKII and SAPAP4) that are translationally repressed by FMRP ${ }^{8,16}$. Thus far, our experiments indicate that FMRP can directly interact with the PSD-95 mRNA, but do not address the functional role of this interaction.

We assessed whether PSD-95 mRNA translation was regulated by FMRP, as was previously proposed ${ }^{29}$, by carrying out sucrose gradient fractionation of cytoplasmic (Fig. 4a) and hippocampal (Fig. 4b) brain extracts from wild-type and FMR1 knockout mice. Unexpectedly, the percentage of PSD-95 mRNA associated with polysomes did not change in the FMR1 knockout animals compared with wild-type animals in either whole brain or hippocampal extracts. Although the profile of the negative control, $\beta$-actin (ACTB) mRNA, also remained unchanged, Arc mRNA, which is known to be translationally regulated by $\mathrm{FMRP}^{8}$, showed the expected shift toward a more translationally active polysome pool in FMR1 knockout extracts. We cannot formally rule out the possibility that FMRP changes the translation efficiency of the PSD-95 mRNA without changing the percentage messenger on polysomes (PMP) ratio (for example, by altering miRNA-regulated translation; reviewed in ref. 37). However, because other FMRPregulated mRNAs (such as $A r c$ ) do change their PMP ratio, the above findings indicate that FMRP does not regulate PSD-95 protein synthesis in a manner similar to those of other well-studied FMRP targets.

\section{PSD-95 mRNA is dendritically localized with FMRP in vivo}

It has been estimated that hundreds of mRNAs are present in dendrites, but whether the entire population or only a subset are localized near synapses is currently unknown ${ }^{38}$. Because this list includes mRNAs that are known targets of FMRP (for example, Arc, $\alpha$ CaMKII), and because PSD-95 is an integral component of the postsynaptic density, we assessed whether the PSD-95 message was localized in dendrites and, if so, whether this localization was dependent on FMRP.

By analyzing the presence of PSD-95 mRNA in synaptoneurosomes from total brain, we found that PSD-95 mRNA showed a marked dendrite/soma enrichment ratio (Supplementary Fig. 2 online), suggesting that the mRNA was localized at synapses. This was further confirmed by in situ hybridization in neuronal cultures (Fig. 5). We found that PSD-95 mRNA localized in both cell bodies and along dendrites of hippocampal (Fig. 5a) and cortical (data not shown) neurons with a typical punctate pattern. Similarly, a recent large-scale screen also suggested putative targeting of the PSD-95 mRNA to both proximal and distal dendrites ${ }^{39}$. Unexpectedly, although PSD-95 mRNA largely colocalized with FMRP throughout the cell and into neurites (Fig. 5a), the PSD-95 mRNA was still localized in dendrites from FMR1 knockout hippocampal (Fig. 5a) and cortical (data not shown) cultures. Control experiments indicated that we could specifically detect dendritic ( $\alpha$ CaMKII) and cell body $\left(\alpha\right.$-tubulin) mRNAs ${ }^{38}$ (Fig. 5b), and that the sense probes did not show any specific mRNA staining (Supplementary Fig. 3 online). These data further confirm that the PSD-95 message is part of an FMRP mRNP complex, but suggest that FMRP function is not necessary to localize the PSD-95 message.

We confirmed that PSD-95 mRNA was dendritically localized using both digoxigenin (DIG) RNA labeling (data not shown) and radioactive in situ hybridization (Fig. 6) on brain slices. PSD-95 mRNA was present in the hippocampus, cortex (Fig. 6a) and cerebellum (Fig. 6b). The unlocalized control mRNA ( $\alpha$-tubulin) stained only cell bodies in the hippocampus and dentate gyrus (Fig. 6c and Supplementary Fig. 4 online). Although PSD-95 mRNA localization was distinct from another localized mRNA ( $\alpha$ CaMKII; Fig. 6d and Supplementary Fig. 4), PSD-95 mRNA was clearly present in hippocampal dendrites of both wild-type and FMR1 knockout mice in a region corresponding 
a

PSD-95 3' UTR fragment 5 (nt 593-835)

aguggaaggu cuaacugugg cuuuuuuuuu uucugggauu unauuncauu unauuugauu uuauuuuuuu gggaaaaggg gagggauggg ucuggggagu ggggaaugug gaggggggug ggggggcaaa gggucagggg uugggugucc gggagccagg ggaggacgaa augcugccgc cuucugcaau unauunauuu uuuucuuuug agagagugaa aggaagagac agacacuug
Putative G-quartet

.. aaaaggg gagggauggg ucuggggag. .

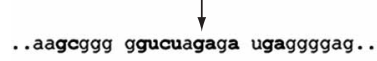

II U-rich

..ggauu unauuucauu unauuugauu unauuuuuuu gg. .

..ggauu ugccgggauc cugugccacg gcaugcguuu gg. .
I U-rich

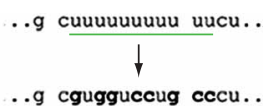

III U-rich
. caau unauuaauuu uuuucu.

. caau ceggcgaugg aagucu.. b

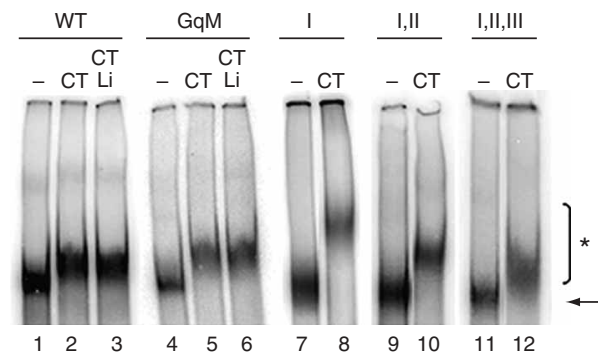

d

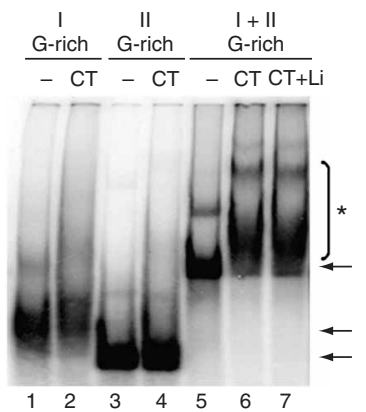

Figure 3 A G-rich region in the PSD-95 3' UTR is responsible for FMRP C-terminus binding. (a) Sequence of fragment 5 (nt 593-835) and mutagenesis of the putative G-quartet and U-rich regions. The first U-rich region is underlined in green, the second U-rich region in yellow, the third U-rich in red and the putative G-quartet in blue. The blue highlighted regions represent two AREs. Bold characters represent introduced substitutions. (b) Wild-type fragment 5 (WT) and the putative G-quartet mutated fragment 5 (GqM) were incubated alone (lanes 1 and 4), with FMRP C terminus (lanes 2 and 5 ) or in the presence of LiCl 50 mM (lanes 3 and 6). The first U-rich mutant (I), the first and second U-rich double mutant (I and II) and the triple U-rich mutant (I, II and III) were incubated alone (lanes 7, 9 and 11) or with the C-terminus (lanes 8, 10, 12). Unbound RNA fragments $(\leftarrow)$ and RNA-protein complexes $\left({ }^{*}\right)$ are indicated. (c) The first G-rich region is highlighted in blue and the second in green. (d) The first G-rich region (nt 666-741) of fragment 5, the second G-rich region (nt 742-786) or the entire G-rich region (nt 666-786) were incubated alone (lanes 1, 3 and 5) or with the C-terminus of FMRP (lanes 2, 4 and 6). The C-terminus and the entire G-rich were incubated in the presence of $50 \mathrm{mM}$ of $\mathrm{LiCl}$ (lane 7).

to the stratum lacunosum-moleculare (Fig. 6a and Supplementary Fig. 4). A control PSD-95 mRNA sense probe did not show any specific mRNA staining (Supplementary Fig. 3). Notably, quantification of PSD-95 mRNA levels showed a clear, though nonsignificant, reduction in hippocampal mRNA in the FMR1 knockout animals relative to cortical mRNA levels (Fig. 6a, $P>0.05$ ). This tendency was not observed when comparing PSD-95 cerebellar with cortical mRNA
(Fig. 6b) or $\alpha$-tubulin hippocampal with cortical mRNA (Fig. 6c) ratios between wild-type and FMR1 knockout mice.

Together, these data provide evidence that the PSD-95 mRNA is localized in dendrites in vitro and in vivo. As there is less PSD-95 mRNA in the stratum lacunosum-moleculare in FMR1 knockout mice (Fig. 6a), we cannot exclude the possibility that FMRP might be involved in a subtle modulation of PSD-95 mRNA localization.
Figure 4 The PSD-95 mRNA polysomal profile is similar in wild-type and $F M R 1$ knockout mice. (a) Cytoplasmic brain extract was fractioned by centrifugation on a $5-70 \%$ sucrose gradient. Ten fractions were collected while 254-nm absorbance was recorded. RNA was extracted from each fraction and visualized on a denaturing agarose gel. rRNA 28S, 18S and 5S/tRNA are shown in each fraction. Radioactive RT-PCR analyses of total RNA in each fraction was carried out with primers specific for PSD-95, $\beta$-actin, Arc and L22 RNAs. The efficiency of translation is reported as a graphic profile of PMP, which was calculated, after normalization to $L 22$, by comparing the radioactivity of the first five fractions containing active polysomes with the radioactivity from all ten fractions. The $P S D-95$, $\beta$-Actin and Arc PMP in each fraction of wild-type or FMR1 knockout gradients was normalized for L22 RNA. (b) Same as in a, using cytoplasmic extracts from the hippocampus. PMP value of three independent experiments with standard error is reported. *, $P<0.05$ for knockout versus wild type by Student's $t$-test. a
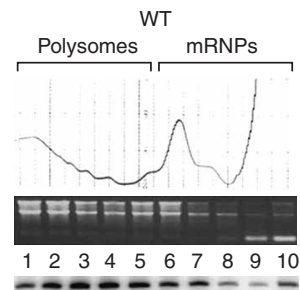

- $==0=-1-\beta-a c t i n$

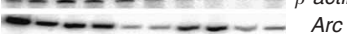

-

b

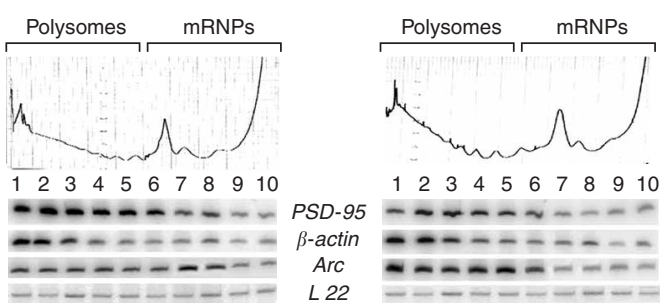

FMR1 KO
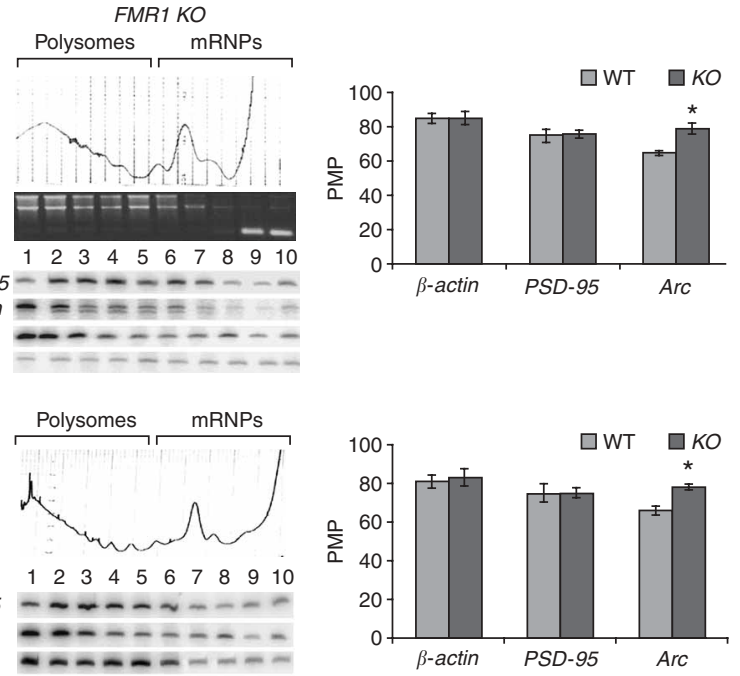
a
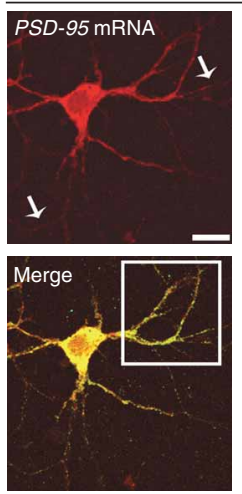

b
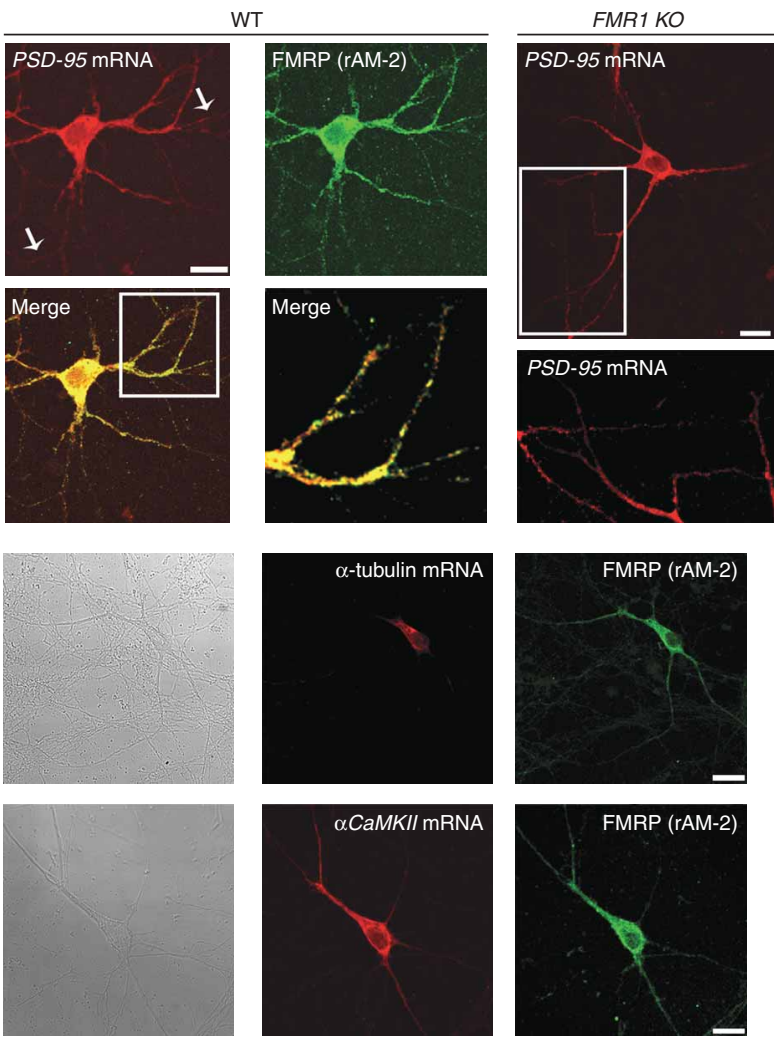

However, as PSD-95 mRNA is clearly present in dendrites in the absence of FMRP (Figs. 5a and 6a), our data suggest that the FMRP does not have a primary role in PSD-95 mRNA localization.

Impaired PSD-95 mRNA and protein levels in FMR1 knockout

Our results suggest that FMRP does not directly regulate translation (Fig. 4) or transport (Figs. 5 and 6) of PSD-95 mRNA. Earlier reports,
Figure 5 PSD-95 mRNA is dendritically localized in neuronal cell cultures. (a) Left, in situ hybridization carried out using an antisense riboprobe specific for PSD-95 mRNA (red), combined with an immunofluorescence for FMRP (green) on wild-type (WT) hippocampal cultures (10 DIV). A merged image and a merged magnification are also shown (yellow). Right, in situ hybridization for PSD-95 in FMR1 knockout hippocampal cultures (top) and magnification (bottom). (b) Upper, bright-field image (left) and in situ hybridization carried out using an antisense riboprobe specific for the cell body-specific $\alpha$-tubulin mRNA (red, middle), combined with an immunofluorescence for FMRP (green, right) on hippocampal cultures (10 DIV). Lower, bright-field image (left) and in situ hybridization carried out using an antisense riboprobe specific for the dendritically localized $\alpha \mathrm{CaMKII}$ mRNA (red, middle), combined with an immunofluorescence for FMRP (green, right) on hippocampal cultures (10 DIV).

however, have suggested that FMRP might also control mRNA abundance via transcriptional regulation ${ }^{15-17}$. Notably, our radioactive in situ hybridization data indicated a possible decrease in PSD-95 mRNA intensity in hippocampal neurons from FMR1 knockout mice (Fig. 6a), suggesting that mRNA abundance may be regulated by FMRP.

To determine whether FMRP controls mRNA abundance, we first examined the total PSD-95 mRNA level in wild-type and FMR1 knockout mice. In total brain, PSD-95 mRNA levels were significantly decreased in FMR1 knockouts compared with wild-type mice (Fig. 7a). Notably, quantitative RT-PCR analyses carried out on the three principal brain areas (hippocampus, cerebellum and cortex) showed that the decrease in PSD-95 mRNA was very pronounced in the hippocampus, less so in the cerebellum and not observed in the cortex (Fig. 7b). Quantitative RT-PCR analyses of the PSD-95 mRNA from hippocampal neurons of wild-type and FMR1 knockout mice confirmed this hippocampal-specific decrease in PSD-95 mRNA (Fig. 7c). Although there was a subtle trend toward lower abundance of PSD-95 mRNA in the hippocampus as detected with radioactive in situ hybridization (Fig. 6), this was not statistically significant, and we believe that these differences may be due to different sensitivities of the techniques. Differential PSD-95 expression was also reflected at a

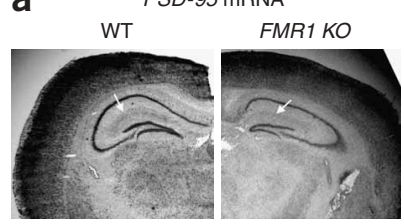

C

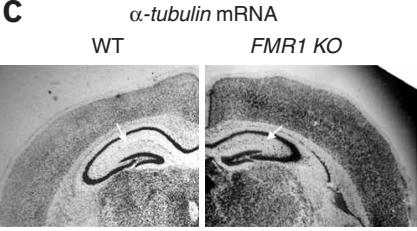

WT
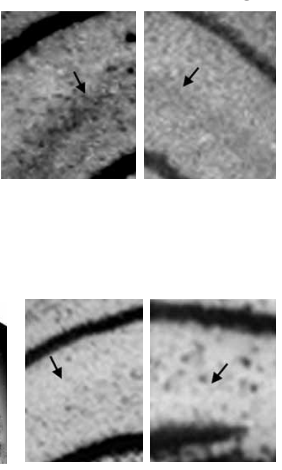
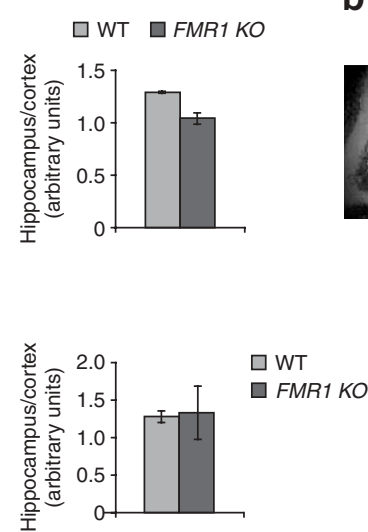

b
WT

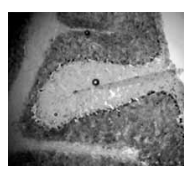

d
FMR1 KO

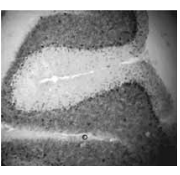

$\square \mathrm{WT} \quad \square$ FMR1 KO

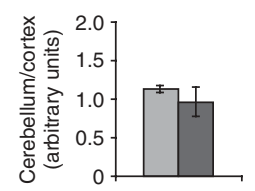

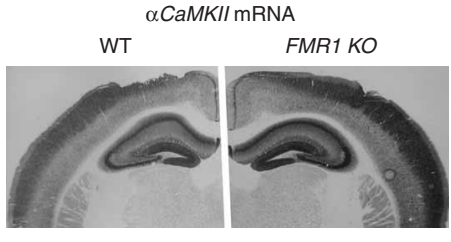

Figure 6 PSD-95 mRNA is dendritically localized in vivo. Radioactive in situ hybridization on transversal brain sections from wild-type (WT; left image in each case) and FMR1 knockout mice (KO; right image in each case) for (a,b) PSD-95, (c) $\alpha$-tubulin and (d) aCaMKI/ mRNAs for PSD-95 mRNA in both wild-type and knockout mice. Arrows point to the stratum lacunosum-moleculare. Right, an enlargement of the CA2 areas marked by the white arrows in the smaller image is shown. Black arrows point to the hippocampal region enriched in PSD-95 mRNA. Quantification of PSD-95 mRNA level in hippocampus relative to cortex is shown (average value from three sections are reported, with s.e.). (a,b) Cerebellar sections are shown. Quantification of PSD-95 mRNA level in cerebellum relative to cortex is shown (average values from three sections are reported, with s.e.). (c) In situ hybridization on brain sections from wild-type and FMR1 knockout mice for $\alpha$-tubulin mRNA. A blown-up of the areas marked by the white arrows is shown. Black arrows indicate the lack of any detectable signal in this area. Quantification of $\alpha$-tubulin mRNA level in hippocampus relative to cortex is shown (average value from three sections are reported, with s.e.). (d) In situ hybridization on brain sections from wild-type and FMR1 knockout mice for $\alpha$ CaMKII mRNA. 
a

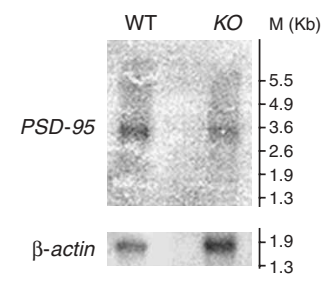

b

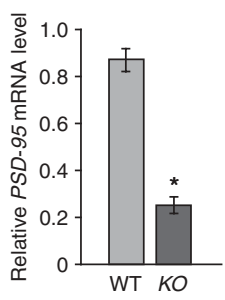

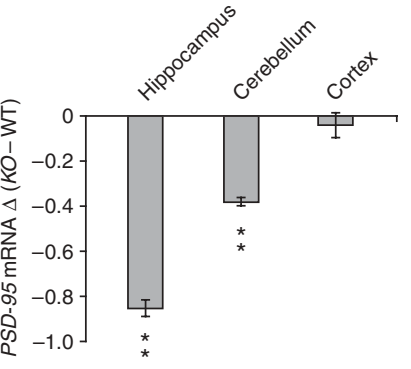

C

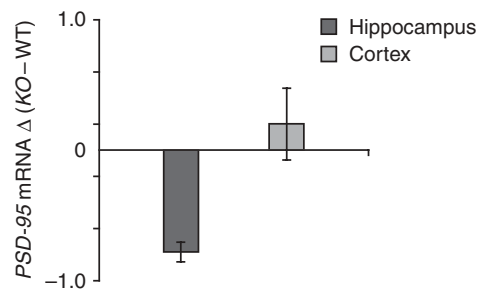

Figure 7 PSD-95 mRNA and protein levels are altered in the FMR1 knockout mice. (a) PSD-95 and $\beta$-actin mRNA levels from total brain were analyzed by northern blotting in wild-type (WT) or FMR1 knockout (KO) mice. The same membrane was hybridized and normalized for $\beta$-actin mRNA (lower). The PSD-95 mRNA/ $\beta$-actin ratio is reported as a histogram with s.e. (b) PSD-95 mRNA levels in three different brain regions were estimated by quantitative RT-PCR from three wild-type and three FMR1 knockout mice, normalized to those of histone $\mathrm{H} 3$ and shown in a histogram as the difference between FMR1 knockout versus wild type values. Error bars represent s.e. (c) The level of PSD-95 mRNA in hippocampal or cortical neuronal cell culture was estimated by quantitative RT-PCR, normalizing the values to histone mRNA. The histogram represents the difference between

the values for FMR1 knockout and wild type, and the bars represent the s.e. of three independent measurements. (d) Protein extracts from cortex, hippocampus or cerebellum of four wild-type and four FMR1 knockout mice were analyzed for PSD-95 and elF4E proteins. Left, western blot from one of the four independent mice analyzed for PSD-95 and elF4E. Right, histogram showing results with s.e. ${ }^{*}, P<0.05$ and ${ }^{* *}, P<0.01$ for knockout versus wild type by Student's $t$-test in all panels.

the protein level, with a statistically significant decrease occurring in the hippocampus and a nonsignificant decrease in the cerebellum (Fig. 7d, $P>0.05$ ).

These data suggest that either transcription or stability of the PSD-95 mRNA is regulated by FMRP in the hippocampus. Critically, the hippocampus is important for the learning processes that are altered in people with FXS ${ }^{40}$, and the loss of PSD-95 results in hippocampaldependent learning defects $^{20}$.

\section{Activity-dependent FMRP control of PSD-95 mRNA stability}

To directly assess whether this change in mRNA level was a result of altered transcription or mRNA stability, we examined the half-life of
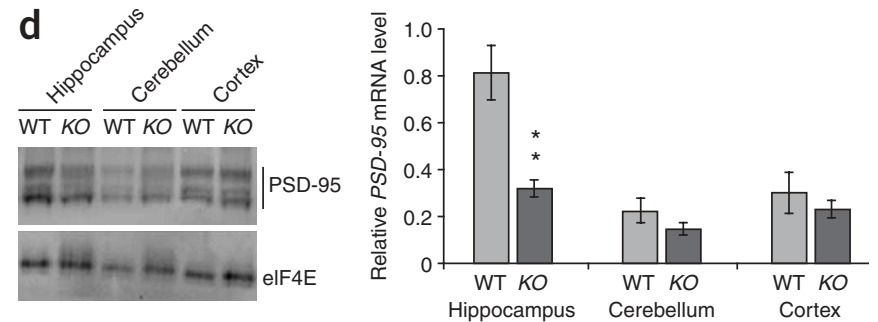

the PSD-95 message in cortical and hippocampal primary cultured neurons. Notably, after transcriptional blockade with actinomycin D, $P S D-95 \mathrm{mRNA}$ abundance was significantly and selectively reduced in hippocampal cultures in the absence of FMRP (Fig. 8a and Supplementary Fig. 5 online). The stability of PSD-95 mRNA was unaffected in FMR1 knockout cortical cultures (Supplementary Fig. 6 online), in agreement with prior results (Fig. $\mathbf{6 a}$ and $\mathbf{7 b}, \mathbf{c}$ ). These results were not due to nonspecific cell death effects, as the morphology of hippocampal cells from wild-type and FMR1 knockout mice were the same (Supplementary Fig. 7 online) and cell survival was the same in both genotypes (Fig. 8b), although we did note that after $12 \mathrm{~h}$ both the wildtype and FMR1 knockout neurons showed some increase in the

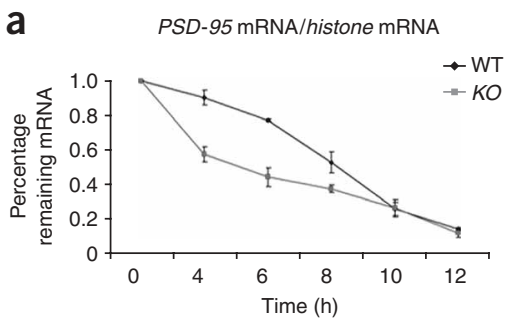

Figure 8 FMRP regulates the stability of PSD-95 mRNA in hippocampal cells through an activity-dependent mechanism. (a) RNA was isolated at the indicated times after actinomycin D application to hippocampal neurons from wild-type or FMR1 knockout mice, and the stability of PSD-95 mRNA was normalized to the values for histone H3 mRNA. (b) MTT assay carried out on wild-type and FMR1 knockout hippocampal cells during the actinomycin $D$ treatments. The s.e. of three measurements for each time point is shown. (c) Stability of a chimeric mRNA containing the Renilla luciferase reporter and either fragment 2 or fragment 5 of PSD-95 3' UTR transfected into wild-type or FMR1 knockout hippocampal neurons. mRNA levels were measured at the indicated times after actinomycin D application by quantitative RT-PCR, with the values normalized to those for histone H3 mRNA. (d) mRNA was isolated at the indicated times after actinomycin D or actinomycin D + DHPG application to hippocampal neurons from wild-type or FMR1 knockout mice. The stability of PSD-95 mRNA in wild-type or FMR1 knockout hippocampal cells was measured by quantitative RT-PCR. $* *, P<0.01$ for knockout versus wild type by Student's $t$-test.
C Luciferase mRNA/histone mRNA

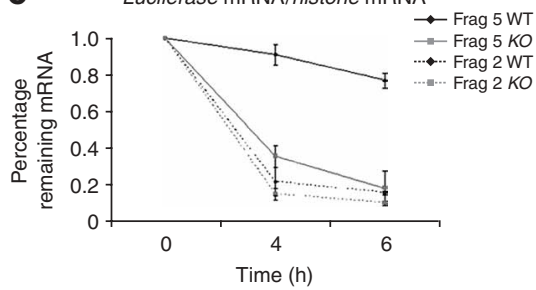

d

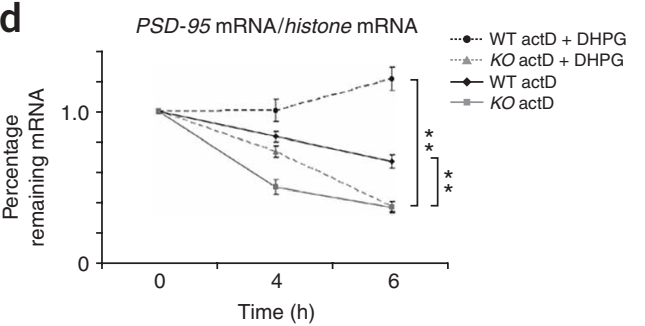


amount of cell death $(\approx 25 \%)$. Together, these results suggest that FMRP functions to stabilize the PSD-95 mRNA specifically in the hippocampus. Furthermore, the stability of a reporter (Renilla reniformis luciferase) RNA carrying the FMRP-interacting portion of the PSD-95 3' UTR (fragment 5) was more stable when transfected into wild-type versus FMR1 knockout hippocampal neurons (Fig. 8c), whereas a reporter RNA containing another PSD-95 3' UTR that does not bind FMRP (fragment 2) was equally unstable in both cultures (Fig. 8c). These data strongly suggest that a direct interaction between FMRP and the PSD-95 $3^{\prime}$ UTR is necessary to confer mRNA stabilization.

Because FMRP has not been previously shown to regulate mRNA stability, we also assessed the stability of 11 other FMRP targets and 2 synaptic scaffolding proteins whose mRNAs are localized in dendrites (Homerla and Shank1). Of these mRNAs (Supplementary Table 1 online), only myelin basic protein mRNA $(M B P)$ changed its stability. $M B P$ mRNA is a target of FMRP regulation ${ }^{41}$, and is present only in glia cells, which also express FMRP ${ }^{8,41}$. We detected the $M B P$ mRNA because our primary neurons were cocultured with glial cells. Notably, although this list is clearly not exhaustive, our analyses suggest that FMRP-mediated mRNA stabilization is a highly selective mechanism with respect to both cell type and target mRNA, and that it works in both neurons and glia.

Because FMRP is regulated by mGluR activation (for example, see refs. 29,42,43), we also investigated whether mGluR stimulation would alter FMRP-dependent PSD-95 mRNA stabilization. Using two independent protocols (see Methods for details), we found that the presence of (S)-3,5-dihydroxyphenylglycine (DHPG) further stabilized PSD-95 mRNA in wild-type cells at both time points measured (Fig. 8d). In FMR1 knockout cells, the addition of DHPG provided only transient stabilization that did not persist at the later time point, suggesting that DHPG might also have a transient, FMRP-independent effect on mRNA half-life. Quantification of three independent experiments indicated that there was a significant DHPG-dependent stabilization effect only in the wild-type neurons and that this effect was mostly lost in FMR1 knockout hippocampal cells (Fig. 8d). Together, the data suggest that there is a long-lasting FMRP-dependent stabilization effect via mGluR-specific neuronal activity.

\section{DISCUSSION}

In this paper we have shown that FMRP interacts directly with the 3' UTR of PSD-95 mRNA. However, we found that PSD-95 mRNA polysomal association remained the same in wild-type and FMR1 knockout mice and that the PSD-95 mRNA was still dendritically localized in FMR1 knockout neurons. Although translation of the PSD95 mRNA may decrease as a result of postinitiation mechanisms (that is, as in the case of some miRNAs; reviewed in ref. 37) that we cannot detect with the current assay, this translation mechanism would be different from that previously documented for other FMRP targets (such as $A r c$ ).

Notably, we found that the FMRP-PSD-95 mRNA interaction resulted in a stabilization of the $P S D-95$ message that can be further increased via mGluR stimulation. In FMR1 knockout mice the PSD-95 message was less stable, resulting in a reduction of this critical synaptic protein. These observations are consistent with previous circumstantial evidence suggesting that FMRP could potentially control mRNA abundance. A microarray study identified 113 FMRP-associated mRNAs whose abundances are reduced in fragile $\mathrm{X}$ cell lines, yet whose polysome profile remained unchanged ${ }^{16}$. Another study found decreases in the levels of some FMRP-target mRNAs in the absence of $\mathrm{FMRP}^{17}$. Although neither group examined these mRNAs further, it is possible that reduced levels of these mRNAs actually reflect a loss of mRNA stability in the absence of FMRP. Our finding that at least one other mRNA $(M B P)$ was destabilized in the absence of FMRP lends support to this idea.

Unexpectedly, we found that the stabilization of the PSD-95 message was dependent on the area of the brain examined. The effect was most prominent in the hippocampus, present to a minor extent in cerebellum and nonexistent in the cortex. This lack of a cortical effect is consistent with previous findings that PSD-95 protein levels are the same in wild-type and FMR1 knockout cortical cells ${ }^{29}$. That study also observed an FMRP-dependent increase in PSD-95 protein in cortical cells shortly after DHPG treatment, but found that protein levels fell back to baseline by $4 \mathrm{~h}^{29}$, suggesting that there was a transient surge in PSD-95 expression. In hippocampal neurons, we observed that the relative level of the PSD-95 mRNA rose slightly after 4-6 h of DHPG exposure, suggesting that there is an additional activity-dependent increase in RNA stability. Together, these data suggest that FMRP can regulate, according to the physiological state (DHPG-treated or not) and cell type (cortical or hippocampal), both a rapid rise in PSD-95 translation (cortex) and a more prolonged rise in PSD-95 mRNA levels as a result of an increase in stability (hippocampus), and suggest that FMRP could have multiple independent roles.

We have mapped the binding site of FMRP to a G-rich element that is flanked by two AU-rich elements (AREs), well-known cis-acting mRNA elements that regulate mRNA half-life. Several trans-acting factors that aid in both stabilization and destabilization of target mRNAs are known to bind to $\mathrm{AREs}^{44}$. Notably, regulation of $\mathrm{HuD}$, a member of the $\mathrm{Hu}$ class of ARE-binding proteins ${ }^{44}$, during neuronal development results in temporal regulation of GAP-43 (ref. 45). Similarly, regulation of mRNA stability is often the result of competition between stabilizing and destabilizing factors ${ }^{44}$. It is therefore plausible that the region-specific regulation of the PSD-95 message is a result of interference between the stabilizing role of FMRP and the stabilizing and destabilizing functions of other binding factors. In support of this notion, we found that the hippocampus and cortex contained different forms of Hu-family proteins (Supplementary Fig. 8 online). Combinatorial models are an emerging theme explaining RNA-protein binding specificity (reviewed in ref. 46,47), and in our case may explain why FMRP does not stabilize all of its known binding targets (Supplementary Table 1).

We also found that the PSD-95 mRNA was localized in dendrites in vivo, but that its localization was not dependent on FMRP, further highlighting the complexity surrounding FMRP's many roles in the cytoplasm. Several factors are known to bind to FMRP and are presumed to aid it in these cytoplasmic regulatory functions. To date, however, only one of these interactions has been shown to aid FMRP function. Cooperative binding between FMRP and the $B C 1$ RNA leads to the translational repression of a subset of mRNAs, and $B C 1$ functions as a repressor of translational initiation in rabbit reticulocyte assays ${ }^{3}$. We expect further binding partners to collaborate with FMRP to aid translational repression, mRNP localization and this newly identified mRNA stabilization function.

Although a large number of putative FMRP target mRNAs have been isolated in the past 5 years, relatively few are known to be involved in regulating synapse structure and function. Our results strengthen the idea that FMRP function is extremely important for the correct formation of the postsynaptic compartment. These results also support the notion that the underlying cause of FXS, and potentially other forms of mental retardation, may involve direct interference with synaptic signaling that leads to spine dysmorphogenesis and ultimately to memory defects ${ }^{1}$. Notably, the mRNA encoding a PSD-95 associated 
protein, SAPAP4, has also been shown to be in a complex with FMRP16. In addition, PSD-95, SAPAP4, Arc and $\alpha$ CaMKII are all components of the large-scale NMDA receptor signaling complex that links NMDA receptors to the mGluR signaling pathway ${ }^{23}$, and disruption of PSD-95 (ref. 20), $A r c^{48}$ and $\alpha C a M K I I$ (ref. 22) all result in learning impairments. This is of interest in light of the evidence suggesting that alterations in glutamate receptor signaling via mGluRs might underlie a number of the cognitive deficits associated with $\mathrm{FXS}^{23}$. Furthermore, various other cases of neurological deficits also result in a decrease in PSD-95 expression (for example, refs. 49,50), suggesting that strict regulation of PSD-95 expression is required for proper brain function. PSD-95 is important in both behavioral memory and dendritic spine morphology $y^{27}$, both features of FXS. Together, these results suggest that FMRP may regulate NMDA and mGluR receptor signaling through several proteins, including PSD-95, and that the cognitive and anatomical defects in FXS may arise from the disruption of this complex.

\section{METHODS}

Animal treatment. Animal care conformed to institutional guidelines in compliance with national and international laws and policies (European Community Council Directive 86/609, Oja L 358,1, December 12, 1987; NIH Guide for the Care and Use of Laboratory Animals). All animals were 3-weekold males (C57/BL6 wild type and two FMR1 knockout strains on C57/BL6 and FVB background).

Western blots. We used standard methodologies with an FMRP monoclonal antibody (MAB2160) from Chemicon and a polyclonal antibody (rAM2) produced in our laboratory ${ }^{8}$. The PSD-95 antibody was from Upstate $(1: 1,000)$ and the eIF4E antibody from Cell Signaling $(1: 10,000)$. All secondary antibodies were from Promega. The proteins were revealed using ECL Plus and a phosphoimager (both from Amersham).

cDNA constructs. We obtained a mouse PSD-95 cDNA construct with the $3^{\prime}$ UTR from the IMAGE consortium (ID 10318) and also isolated PSD-95 coding and 3' UTR fragments via RT-PCR from mouse brain extract and T/A cloning (Promega Easy T/A cloning kit; pT/A-Fragment 1-5). Details of constructs and mutagenesis are reported in the Supplementary Methods online. FMRP protein domains were previously reported ${ }^{34}$.

EMSA. We carried out binding reactions using full-length human FMRP protein in binding buffer $(300 \mathrm{mM} \mathrm{KCl}, 5 \mathrm{mM} \mathrm{MgCl}, 2 \mathrm{mM}$ DTT, $0.5 \%$ glycerol, $20 \mathrm{mM}$ HEPES pH 7.5 and $300 \mathrm{ng} \mathrm{ml}^{-1} \mathrm{tRNA}$ ), incubating at $25^{\circ} \mathrm{C}$ or $4{ }^{\circ} \mathrm{C}$ for $30 \mathrm{~min}$. We added heparin $(0.3 \mathrm{mg})$ for $5 \mathrm{~min}$ before separation on a $6 \%$ native polyacrylamide gel. We carried out binding reactions with FMRP domains in the same buffer plus 100 or $300 \mathrm{mM} \mathrm{KCl}$ and 50-100-ng recombinant protein.

In vitro transcription. We carried out these reactions using standard protocols (Ambion SP6/T7 Mega-Script) with $\left[\alpha_{-}{ }^{32} \mathrm{P}\right] \mathrm{UTP},\left[\alpha_{-}{ }^{35} \mathrm{~S}\right] \mathrm{UTP}$ and UTP-Cy5 for EMSA, northern blotting and in situ hybridization, respectively.

Primary cultures. We prepared primary cortical and hippocampal neuronal cultures from embryonic mice (embryonic day 15, cortical; embryonic day 19, hippocampal) using standard protocols.

Neuronal transfection. We transfected hippocampal neurons at 14 days in vitro (DIV) using a standard $\mathrm{Ca}^{2+}$ phosphate precipitation protocol. We washed the precipitate using Hanks' balanced saline (HBSS) and carried out actinomycin D experiments $48 \mathrm{~h}$ later.

FISH, immunofluorescence and immunohistochemistry. We fixed primary hippocampal and cortical neurons at $20-25{ }^{\circ} \mathrm{C}$ for $15 \mathrm{~min}$ ( $4 \%$ paraformaldehyde, $2 \mathrm{mM} \mathrm{MgCl}_{2}, 5 \mathrm{mM}$ EGTA in $1 \times$ PBS) and then UV irradiated and permeabilized the cells ( $1 \times$ PBS containing $0.1 \%$ Triton X-100). We prehybridized neurons $\left(50 \%\right.$ formamide, $2 \times \mathrm{SSC}, 10 \mathrm{mM} \mathrm{NaH} \mathrm{NO}_{3}$ ) and then hybridized at $42{ }^{\circ} \mathrm{C}\left(30 \%\right.$ formamide, $10 \mathrm{mM} \mathrm{NaH}_{2} \mathrm{PO}_{3}, 10 \%$ dextran sulfate, $2 \times$ SSC, $0.2 \%$ BSA, $0.5 \mathrm{mg} \mathrm{ml}^{-1}$ yeast tRNA and $500 \mu \mathrm{g} \mathrm{ml}^{-1}$ salmon sperm
DNA, and in vitro synthesized Cy5-labeled riboprobe). We carried out immunofluorescence and immunohistochemistry preincubation in 2\% donkey serum, $0.2 \%$ Triton X-100, and then incubation in $1 \%$ BSA with antibodies specific for FMRP antibodies 8 , followed by Cy3-labeled secondary antibodies specific for rabbit IgG (Jackson ImmunoResearch). We analyzed neurons by confocal scanning microscopy (Zeiss LSM 510).

Radioactive in situ hybridization. We cryostat sectioned, fixed (4\% paraformaldehyde), permeabilized ( $1 \mathrm{mg} \mathrm{ml}^{-1}$ proteinase $\left.\mathrm{K}\right)$ and acetylated $(0.25 \%$ of acetic anhydride in $0.1 \mathrm{M}$ triethanolamine, $\mathrm{pH}$ 8.0) brains before prehybridization and hybridization using standard protocols $\left(55{ }^{\circ} \mathrm{C}\right.$ in $50 \%$ formamide, $1 \times$ Denhardt's solution, $10 \%$ dextran sulfate, $0.3 \mathrm{M} \mathrm{NaCl}, 5 \mathrm{mM}$ EDTA, $0.5 \mathrm{mg} \mathrm{ml}^{-1}$ yeast tRNA, $20 \mathrm{mM}$ Tris $\mathrm{HCl} \mathrm{pH} \mathrm{8.0,50} \mathrm{mM} \mathrm{DTT} \mathrm{and} 10^{5}$ $\mathrm{cpm} \mu \mathrm{l}^{-1}$ of $\left[\alpha^{-}{ }^{35} \mathrm{~S}\right] \mathrm{UTP}-$ riboprobe). Slides were emulsified (Kodak autoradiography emulsion NTB2) and developed (ILFORD PQ developer) after 7-15 d of exposition. We analyzed sections by microscopy using a Zeiss Axioskop $(1.25 \times$ or $5 \times$ objectives), acquired images with a Canon S50 digital camera and quantified the signal using ImageQuant and ImageJ.

Immunoprecipitation and RT-PCR. Whole brain was homogenized in $10 \mathrm{mM}$ HEPES pH 7.4, $200 \mathrm{mM} \mathrm{NaCl}, 0.5 \%$ Triton X-100, 30 mM EDTA, protease inhibitors (Sigma-Aldrich) and $30 \mathrm{U} \mathrm{ml}^{-1}$ RNasin. We preblocked $20 \mu \mathrm{l}$ protein A-Sepharose $\left(0.1 \mathrm{mg} \mathrm{ml}^{-1}\right.$ BSA, $0.1 \mathrm{mg} \mathrm{m}^{-1}$ yeast tRNA and $0.1 \mathrm{mg} \mathrm{ml}^{-1}$ glycogen) for $1 \mathrm{~h}$ and then immunoprecipitated with specific FMRP antibodies $^{8}$. DNase I (RNase-free, Amersham Pharmacia Biotech) was added during washes. We treated the immunoprecipitate with $50 \mu \mathrm{g}$ proteinase $\mathrm{K}$ (Sigma-Aldrich) before RNA extraction and precipitation. First-strand synthesis was performed using $\mathrm{p}(\mathrm{dN}) 6$ and $100 \mathrm{U}$ of M-MLV RTase (Invitrogen). RT-PCR was performed as described in ref. 8. Radioactive semiquantitative RT-PCR reactions were performed in nonsaturating conditions in the presence of $0.2 \mu^{\mathrm{Ci}}\left[\alpha_{-}{ }^{32} \mathrm{P}\right] \mathrm{dCTP}, 1 \mathrm{mM}$ dCTP and $10 \mathrm{mM}$ each dATP, dGTP and dTTP and analyzed on a $5 \%$ polyacrylamide gel.

Reversible cross-linking. We performed experiments as previously described ${ }^{32}$. Briefly, we washed hippocampal neurons at 10 DIV with Neurobasal medium containing $2 \%$ B27, and cross-linked them in $0.5 \%$ formaldehyde (J.T. Baker) for $30 \mathrm{~min}$ at $20-25{ }^{\circ} \mathrm{C}$ and quenched with $0.25 \mathrm{M}$ glycine (Bio-Rad). We harvested cells by centrifugation, PBS washing and resuspension in RIPA buffer (see ref. 32). We immunoprecipitated cross-linked complexes with an FMRP antibody ${ }^{8}$. Before RT-PCR, we reversed cross-linking by treatment at $70{ }^{\circ} \mathrm{C}$.

Polysomal analysis and RT-PCR. We analyzed cytoplasmic brain extract (of total brain and hippocampi) as previously described ${ }^{8}$. See Supplementary Methods for details.

mRNA stability assay. We treated primary cortical or hippocampal cultures (10 DIV) from time 0 with actinomycin $\mathrm{D}\left(10 \mu \mathrm{g} \mathrm{m}^{-1}\right)$ for the indicated times. We washed cultures in PBS, extracted RNA with Trizol and analyzed RNA by quantitative RT-PCR. We used a NIKON C1 with plan-neofluar $20 \times$ to analyze both wild-type and FMR1 knockout cultures for morphology. We assessed mRNA stability after DHPG treatment in two different ways. First, we added DHPG $(100 \mu \mathrm{M})$ to cultures pre-exposed to actinomycin D for $3.5 \mathrm{~h}$ or $5.5 \mathrm{~h}$. After 30 min of DHPG treatment, we collected mRNA for quantitative RT-PCR analysis. Second, we added DHPG $(50 \mu \mathrm{M})$ and actinomycin D jointly to cells at time 0 and collected RNA 4 or $6 \mathrm{~h}$ later for quantitative RT-PCR analysis.

Quantitative RT-PCR. We carried out reactions with MoMLV-reverse transcriptase (Invitrogen) and the TaqMan Universal PCR Master Mix (ABI 4304437) using dual-labeled TaqMan probes (Applied Biosystems). We detected mouse PSD-95 mRNA using the Pre-Developed TaqMan probe Mm00492193_ml and compared with the endogenous control mRNA (mouse H3f3b mRNA Pre-Developed TaqMan probe Mm00787223_s1). Cycle parameters were as suggested by the manufacturer. Relative PSD-95 mRNA levels, normalized to $H 3 f 3 b$, were calculated as follows: $2^{-[\text {DeltaCt(treated) }-}$ DeltaCt(untreated) $]=2^{\text {-DeltaCt }}$, where DeltaCt equals $\mathrm{Ct}(P S D-95)-\mathrm{Ct}(H 3 f 3 b)$. $\beta$-actin mRNA was detected with Pre-Developed TaqMan probe 
Mm00607939_s1, and Renilla luciferase mRNA was detected using primers specifically designed by Applied Biosystems (See Supplementary Methods).

Primers. We provide a table listing the primers used in this study in the Supplementary Methods.

Neuronal cell survival (mitochondrial activity). We measured the mitochondrial activity using the colorimetric MTT assay by incubating hippocampal cultures for $30 \mathrm{~min}$ at $37{ }^{\circ} \mathrm{C}$ with $1 \mathrm{ml}$ of Locke's buffer $(154 \mathrm{mM} \mathrm{NaCl}$, $5.6 \mathrm{mM} \mathrm{KCl}, 3.6 \mathrm{mM} \mathrm{NaHCO} 3,2.3 \mathrm{mM} \mathrm{CaCl}_{2}, 1.2 \mathrm{mM} \mathrm{MgCl}_{2}, 5.6 \mathrm{mM}$ glucose, $5 \mathrm{mM}$ HEPES, pH 7.4) containing $300 \mu \mathrm{g}$ MTT (3-(4,5-dimethylthiazol-2-yl)-2,5-diphenyl tetrazolium, Sigma). We then dissolved cultures with $700 \mu \mathrm{l}$ of DMSO and tested viable neurons by production of the purple MTT cleavage product, formazan. We took three independent measurements of sample optical density using a VICTOR 3V 1420 Multilabel Counter at $490 \mathrm{~nm}$ and reported the mean with s.d. The value of each culture is divided by the reference value (control culture at time 0 ).

Northern blot analysis. We probed $2 \mu \mathrm{g}$ of poly $(\mathrm{A})^{+} \mathrm{RNA}$ from the entire brain or $20 \mu \mathrm{g}$ of total RNA using a mouse $\left[\alpha^{-}{ }^{32} \mathrm{P}\right] \mathrm{UTP}$ PSD-95 mRNA antisense probe to fragment 5 (nucleotides (nt) 2,820-3,061 of BC014807), the entire $3^{\prime}$ UTR (nt 2,227-3,061 from BC014807) or the coding region (nt $61-2,226$ of BC014807). We probed the same membrane with a $\beta$-actin cDNA antisense fragment (nt 258-837 of X03672) and quantified radioactive signals with a phosphoimager (Amersham).

Note: Supplementary information is available on the Nature Neuroscience website.

\section{ACKNOWLEDGMENTS}

We thank B.A. Oostra for the FMR1 knockout mice, N.K. Gray and T. Achsel for their critical evaluation of the manuscript, and O. Steward for precious suggestions and reagents. We thank M.A. Kiebler for advice on the neuronal transfection protocol. This research was funded by a European Molecular Biology Organization short-term fellowship, a Royal Society of Edinburgh Scottish Executive Enterprise and Lifelong Learning Department fellowship and a Biotechnology and Biological Sciences Research Council grant (C19143) to K.S.D., by Telethon (GGP05269), Ministero della Salute, Ministero della Università (FIRB) to C.B. and by Wellcome Trust grant number 056523 and the Wellcome Trust Genes to Cognition Programe to S.G.N.G. F.Z. was supported by the Associazione Italiana Sindrome dell'X Fragile.

\section{AUTHOR CONTRIBUTIONS}

F.Z. contributed to the conclusions drawn in Figures 1, 4, 6, 7 and 8. B.E. contributed to the conclusions drawn from Figures 5-8. K.S.D. provided intellectual input, contributed to the conclusions drawn from Figures 1-3 and 8, contributed a portion of the funding and contributed to the writing of this manuscript. V.M. contributed to the conclusions drawn from Figures 5-7. S.D.R. contributed to the conclusions drawn from Figures 2, 3 and 7. A.D.P. contributed to the conclusions drawn from Figures 1 and 7. E.T. and P.C. contributed to the conclusions drawn from Figures 7 and 8. G.N. contributed with intellectual inputs. S.G.N.G. contributed some initial funding for this work and intellectual inputs. C.B. provided intellectual input, funding, coordination of the project and contributed to the writing of this manuscript.

\section{COMPETING INTERESTS STATEMENT}

The authors declare no competing financial interests.

Published online at http://www.nature.com/natureneuroscience

Reprints and permissions information is available online at http://npg.nature.com/ reprintsandpermissions

1. Bagni, C. \& Greenough, W.T. From mRNP trafficking to spine dysmorphogenesis: the roots of fragile X syndrome. Nat. Rev. Neurosci. 6, 376-387 (2005).

2. Darnell, J.C., Mostovetsky, O. \& Darnell, R.B. FMRP RNA targets: identification and validation. Genes Brain Behav. 4, 341-349 (2005).

3. Zalfa, F., Achsel, T. \& Bagni, C. mRNPs, polysomes or granules: FMRP in neuronal protein synthesis. Curr. Opin. Neurobiol. 16, 265-269 (2006).

4. Darnell, J.C. et al. Fragile $\mathrm{X}$ mental retardation protein targets G-quartet mRNAs important for neuronal function. Cell 107, 489-499 (2001).

5. Schaeffer, C. et al. The fragile $X$ mental retardation protein binds specifically to its $\mathrm{mRNA}$ via a purine quartet motif. EMBO J. 20, 4803-4813 (2001).

6. Ramos, A., Hollingworth, D. \& Pastore, A. G-quartet-dependent recognition between the FMRP RGG box and RNA. RNA 9, 1198-1207 (2003).
7. Chen, L., Yun, S.W., Seto, J., Liu, W. \& Toth, M. The fragile X mental retardation protein binds and regulates a novel class of mRNAs containing U-rich target sequences. Neuroscience 120, 1005-1017 (2003).

8. Zalfa, F. et al. The fragile $X$ syndrome protein FMRP associates with BC1 RNA and regulates the translation of specific mRNAs at synapses. Cell 112, 317-327 (2003).

9. Gabus, C., Mazroui, R., Tremblay, S., Khandjian, E.W. \& Darlix, J.L. The fragile X mental retardation protein has nucleic acid chaperone properties. Nucleic Acids Res. 32, 2129-2137 (2004).

10. Zalfa, F. et al. Fragile X mental retardation protein (FMRP) binds specifically to the brain cytoplasmic RNAs BC1/BC200 via a novel RNA-binding motif. J. Biol. Chem. 280, 33403-33410 (2005).

11. Johnson, E.M. et al. Role of Pur alpha in targeting mRNA to sites of translation in hippocampal neuronal dendrites. J. Neurosci. Res. 83, 929-943 (2006).

12. Jin, P., Alisch, R.S. \& Warren, S.T. RNA and microRNAs in fragile $X$ mental retardation. Nat. Cell Biol. 6, 1048-1053 (2004).

13. Darnell, J.C. et al. Kissing complex RNAs mediate interaction between the fragile $X$ mental retardation protein $\mathrm{KH} 2$ domain and brain polyribosomes. Genes Dev. 19, 903-918 (2005).

14. Kanai, Y., Dohmae, N. \& Hirokawa, N. Kinesin transports RNA: isolation and characterization of an RNA-transporting granule. Neuron 43, 513-525 (2004).

15. Zhong, N., Ju, W., Nelson, D., Dobkin, C. \& Brown, W.T. Reduced mRNA for G3BP in fragile X cells: evidence of FMR1 gene regulation. Am. J. Med. Genet. 84, 268-271 (1999).

16. Brown, V. et al. Microarray identification of FMRP-associated brain mRNAs and altered mRNA translational profiles in fragile X syndrome. Cell 107, 477-487 (2001).

17. Miyashiro, K.Y. et al. RNA cargoes associating with FMRP reveal deficits in cellular functioning in Fmr1 null mice. Neuron 37, 417-431 (2003).

18. Huber, K.M., Gallagher, S.M., Warren, S.T. \& Bear, M.F. Altered synaptic plasticity in a mouse model of fragile $X$ mental retardation. Proc. Natl. Acad. Sci. USA 99, 7746-7750 (2002).

19. Tonegawa, S. et al. Hippocampal CA1-region-restricted knockout of NMDAR1 gene disrupts synaptic plasticity, place fields and spatial learning. Cold Spring Harb. Symp. Quant. Biol. 61, 225-238 (1996).

20. Migaud, M. et al. Enhanced long-term potentiation and impaired learning in mice with mutant postsynaptic density-95 protein. Nature 396, 433-439 (1998).

21. Fagiolini, M. et al. Separable features of visual cortical plasticity revealed by $N$-methylD-aspartate receptor 2A signaling. Proc. Natl. Acad. Sci. USA 100, 2854-2859 (2003).

22. Silva, A.J., Paylor, R., Wehner, J.M. \& Tonegawa, S. Impaired spatial learning in $\alpha$-calcium-calmodulin kinase II mutant mice. Science 257, 206-211 (1992).

23. Husi, H., Ward, M.A., Choudhary, J.S., Blackstock, W.P. \& Grant, S.G. Proteomic analysis of NMDA receptor-adhesion protein signaling complexes. Nat. Neurosci. 3, 661-669 (2000).

24. Sheng, M. \& Kim, M.J. Postsynaptic signaling and plasticity mechanisms. Science 298, 776-780 (2002).

25. Cuthbert, P.C. et al. SAP102/dlgh3 couples the NMDA receptor to specific plasticity pathways and learning strategies. J. Neurosci. 27, 2673-2682 (2007).

26. Tarpey, P. et al. Mutations in the DLG3 gene cause nonsyndromic X-linked mental retardation. Am. J. Hum. Genet. 75, 318-324 (2004).

27. Vickers, C.A. et al. Neurone specific regulation of dendritic spines in vivo by post synaptic density-95 protein (PSD-95). Brain Res (2006).

28. Reiss, A.L., Lee, J. \& Freund, L. Neuroanatomy of fragile $X$ syndrome: the temporal lobe. Neurology 44, 1317-1324 (1994).

29. Todd, P.K., Mack, K.J. \& Malter, J.S. The fragile X mental retardation protein is required for type-I metabotropic glutamate receptor-dependent translation of PSD-95. Proc. Natl. Acad. Sci. USA 100, 14374-14378 (2003).

30. Zhang, Y.Q. et al. Drosophila fragile X-related gene regulates the MAP1B homolog Futsch to control synaptic structure and function. Cell 107, 591-603 (2001).

31. Lu, R. et al. The fragile X protein controls microtubule-associated protein $1 B$ translation and microtubule stability in brain neuron development. Proc. Natl. Acad. Sci. USA 101 15201-15206 (2004).

32. Niranjanakumari, S., Lasda, E., Brazas, R. \& Garcia-Blanco, M.A. Reversible crosslinking combined with immunoprecipitation to study RNA-protein interactions in vivo. Methods 26, 182-190 (2002).

33. Bence, M., Arbuckle, M.I., Dickson, K.S. \& Grant, S.G. Analyses of murine postsynaptic density-95 identify novel isoforms and potential translational control elements. Brain Res. Mol. Brain Res. 133, 143-152 (2005).

34. Adinolfi, S. et al. Dissecting FMR1, the protein responsible for fragile $X$ syndrome, in its structural and functional domains. RNA 5, 1248-1258 (1999).

35. Williamson, J.R., Raghuraman, M.K. \& Cech, T.R. Monovalent cation-induced structure of telomeric DNA: the G-quartet model. Cell 59, 871-880 (1989).

36. Klann, E. \& Dever, T.E. Biochemical mechanisms for translational regulation in synaptic plasticity. Nat. Rev. Neurosci. 5, 931-942 (2004).

37. Pillai, R.S., Bhattacharyya, S.N. \& Filipowicz, W. Repression of protein synthesis by miRNAs: how many mechanisms? Trends Cell Biol. 17, 118-126 (2007).

38. Steward, O.\& Schuman, E.M. Compartmentalized synthesis and degradation of proteins in neurons. Neuron 40, 347-359 (2003).

39. Lein, E.S. et al. Genome-wide atlas of gene expression in the adult mouse brain. Nature 445, 168-176 (2007).

40. Loesch, D.Z., Huggins, R.M. \& Hagerman, R.J. Phenotypic variation and FMRP levels in fragile X. Ment. Retard. Dev. Disabil. Res. Rev. 10, 31-41 (2004).

41. Wang, H. et al. Developmentally-programmed FMRP expression in oligodendrocytes: a potential role of FMRP in regulating translation in oligodendroglia progenitors. Hum. Mol. Genet. 13, 79-89 (2003). 
42. Weiler, I.J. et al. Fragile $X$ mental retardation protein is translated near synapses in response to neurotransmitter activation. Proc. Natl. Acad. Sci. USA 94, 5395-5400 (1997)

43. Antar, L.N., Afroz, R., Dictenberg, J.B., Carroll, R.C. \& Bassell, G.J. Metabotropic glutamate receptor activation regulates fragile $\mathrm{X}$ mental retardation protein and FMR1 mRNA localization differentially in dendrites and at synapses. J. Neurosci. 24, 2648-2655 (2004).

44. Barreau, C., Paillard, L. \& Osborne, H.B. AU-rich elements and associated factors: are there unifying principles? Nucleic Acids Res. 33, 7138-7150 (2005).

45. Smith, C.L. et al. GAP-43 mRNA in growth cones is associated with HuD and ribosomes. J. Neurobiol. 61, 222-235 (2004).
46. Singh, R. \& Valcarcel, J. Building specificity with nonspecific RNA-binding proteins. Nat. Struct. Mol. Biol. 12, 645-653 (2005).

47. Ule, J. \& Darnell, R.B. RNA binding proteins and the regulation of neuronal synaptic plasticity. Curr. Opin. Neurobiol. 16, 102-110 (2006).

48. Plath, N. et al. Arc/Arg3.1 is essential for the consolidation of synaptic plasticity and memories. Neuron 52, 437-444 (2006).

49. Gylys, K.H. et al. Synaptic changes in Alzheimer's disease: increased amyloid-beta and gliosis in surviving terminals is accompanied by decreased PSD-95 fluorescence. Am J. Pathol. 165, 1809-1817 (2004).

50. Toro, C. \& Deakin, J.F. NMDA receptor subunit NRI and postsynaptic protein PSD-95 in hippocampus and orbitofrontal cortex in schizophrenia and mood disorder. Schizophr. Res. 80, 323-330 (2005). 